\title{
Observation of a compensation relation for monomolecular alkane cracking by zeolites: the dominant role of reactant sorption
}

\author{
Jeroen A. van Bokhoven , ${ }^{\mathrm{a}, *}$ Bryce A. Williams, ${ }^{\mathrm{b}}$ W. Ji, ${ }^{\mathrm{b}, 1}$ Diek C. Koningsberger, ${ }^{\mathrm{c}}$ \\ Harold H. Kung, ${ }^{\text {b }}$ and Jeffrey T. Miller ${ }^{\mathrm{d}}$ \\ ${ }^{a}$ Institute for Chemical and Bioengineering, Swiss Federal Institute of Technology (ETH), 8093-CH, Zurich, Switzerland \\ b Department of Chemical Engineering, Northwestern University, 2145 Sheridan Road, Evanston, IL 60208-3120, USA \\ ${ }^{\mathrm{c}}$ Department of Inorganic Chemistry and Catalysis, Utrecht University, PO Box 80083, Sorbonnelaan 16, NL 3508 TC, Utrecht, The Netherlands \\ d BP Chemical Company, 150 W. Warrenville Road, Naperville, IL 60563, USA
}

Received 7 November 2003; revised 9 February 2004; accepted 9 February 2004

\begin{abstract}
Monomolecular cracking of alkanes was investigated over zeolites of different structure types and after different treatments. Large deviations in apparent rates of reaction and apparent kinetic parameters were detected for zeolites of different structure types; smaller changes were observed within a structure type. The $\mathrm{Si} / \mathrm{Al}$ ratio and different crystal sizes had no effect on turnover frequency; however, steaming of mordenite and ZSM-5 enhances the rate of reaction by a factor of 2-5 due to the formation of Lewis acid sites with enhanced heat of adsorption, although the number of Brønsted sites decreased. The apparent activation energies and preexponential factors showed a linear compensation relation in a Constable plot. Using the Langmuir-Hinshelwood kinetics formalism, the apparent kinetic parameters include enthalpy and entropy of adsorption and surface reaction terms. If the enthalpy and entropy of adsorption are linearly related, which is experimentally observed for unsteamed and steamed mordenite, then the apparent compensation effect implies that the observed differences in rate are dominated by differences in adsorption of the reactant in the pores of the zeolites, rather than by differences in acid strength. Zeolites with smaller pores show enhanced adsorption, and consequently the rate of reaction increases in the order $\mathrm{H}-\mathrm{Y}<\mathrm{H}-\mathrm{MOR}<\mathrm{H}-\mathrm{ZSM}-5$.

(c) 2004 Elsevier Inc. All rights reserved.
\end{abstract}

Keywords: Monomolecular cracking; Zeolite acidity; ZSM-5; Y; Mordenite; Hexane cracking; Compensation effect; Constable plot

\section{Introduction}

Zeolites are widely utilized as solid acid catalysts in industrial petrochemical processes, for example, fluid catalytic cracking (FCC), hydrocracking, paraffin isomerization, aromatic alkylation, xylene isomerization, and toluene disproportionation [1]. The structure of zeolites is composed of silicon and aluminum oxide tetrahedra. Charge balance requires one cation per aluminum. It is generally accepted that in acidic zeolites, the active site is a proton localized on an oxygen ion coordinated to aluminum; therefore, many studies have been devoted to the determination of the number,

\footnotetext{
* Corresponding author.

E-mail address: j.a.vanbokhoven@chem.ethz.ch (J.A.van Bokhoven).

1 Department of Chemistry and Chemical Engineering, Mesoscopic Chemistry Laboratory, Nanjing University, 22 Hankou Road, Nanjing, 210093 China.
}

nature, and strength of acid sites. Several studies have shown that the catalytic activity increases in direct proportion to the number of strong Brønsted acid sites. For example, in Y zeolite, the catalytic activity for the cracking of hexane $[2,3]$ and isobutane [4] increases linearly with increasing framework aluminum up to $32 \mathrm{Al} /$ unit cell. Similarly, in ZSM-5, the catalytic activity for hexane cracking increases linearly with increasing structural aluminum $[5,6]$.

In addition to the number of acid sites, it is thought that the strength of the Brønsted acid sites is affected by the acid site density, i.e., the $\mathrm{Si} / \mathrm{Al}$ ratio [7], the T-O-T bond angle $[8,9]$, the presence of nonframework aluminum $[2,3$, $8,10-18]$, or charge-balancing cations $[18,19]$. Theoretical and experimental evidence suggests that the acid strength per aluminum is a maximum when the framework aluminum ions have no second nearest neighbor aluminum [20,21]. Similarly, as the T-O-T bond angle decreases, the acid strength increases; thus smaller pore zeolites display higher 
cracking activity per Brønsted site. For example, for many acid-catalyzed reactions the activity increases in the order MFI $>$ MOR $>$ Y. High-temperature steaming of zeolites leads to the loss of structural aluminum and a decrease in the number of acid sites, but an increase in the catalytic activity. The higher activity of the remaining catalytic sites is generally suggested to be due to the presence of enhanced acid strength. For example, enhanced conversion for hexane cracking occurs for mildly steamed H-ZSM-5, mordenite, and $\mathrm{Y}$ zeolite. Steaming also leads to the formation of nonframework aluminum (NF Al) and Lewis acid sites. Highly active sites are thought to form when a nonframework aluminum ion bonds to a framework aluminum-oxygen bond. The Lewis acid center is proposed to withdraw electron density enhancing the Brønsted acid strength [19,22]. Based on Cs poisoning studies [11], it was concluded that about $4 \%$ of the total aluminum present in ZSM-5 has enhanced activity. While ion exchange results in a loss of one Brønsted site per alkali ion, the loss in catalytic activity is greater than the loss in the number of sites. This observation has led to the conclusion that the acid strength of all acid sites, even those that have no second nearest neighbors, is not equal and that the catalytic activity is due to a small number of Brønsted sites with enhanced activity [2].

Paraffin cracking is a model reaction often used to characterize the strength of Brønsted sites in zeolites. Depending on the reaction conditions and conversion, there are two reaction pathways for paraffin cracking. The initial reaction occurs by a monomolecular attack by the Brønsted acid site on $\mathrm{C}-\mathrm{H}$ or $\mathrm{C}-\mathrm{C}$ bonds. This attack results in an (adsorbed) pentacoordinate carbonium ion, which decomposes to a smaller paraffin (or $\mathrm{H}_{2}$ ) and an adsorbed carbenium ion, forming an alkoxy species [23]. Under conditions of low alkane partial pressure, low conversion, and high temperature, i.e., low surface coverage, the alkoxy species desorbs yielding an olefin product. At higher conversions and surface coverage, the adsorbed species undergo bimolecular reaction with a second paraffin reactant abstracting a hydride ion. These adsorbed species undergo isomerization, $\beta$-scission, and alkylation of alkenes.

Under conditions where monomolecular alkane cracking dominates, physical adsorption of alkane reactants contributes to the apparent kinetics and obeys Temkin's relation [24,25]. A Langmuir-Hinshelwood model adequately describes the kinetics of monomolecular cracking. In this model, the kinetically significant elementary steps can be described by Eqs. (1) and (2) for hexane cracking:

$$
\begin{aligned}
& \mathrm{C}_{6} \mathrm{H}_{14} \text { (gas) } \Leftrightarrow \mathrm{C}_{6} \mathrm{H}_{14}(\text { ads }) \\
& \mathrm{C}_{6} \mathrm{H}_{14} \text { (ads) }+\mathrm{H}^{+}{ }_{-}{ }^{-} \mathrm{OZ} \Rightarrow\left[\mathrm{C}_{6} \mathrm{H}_{15}{ }^{+}{ }_{-}{ }^{-} \mathrm{OZ}\right]^{ \pm} \\
& \quad \Rightarrow \text { cracked products. }
\end{aligned}
$$

Hexane is first physically adsorbed into the zeolite [Eq. (1)]. This step is rapid and the adsorbed hexane is in equilibrium with the gas phase. The adsorbed hexane then reacts with a Brønsted site [Eq. (2)] to form a transition state,
$\left[\mathrm{C}_{6} \mathrm{H}_{15}{ }^{+}{ }_{-}^{-} \mathrm{OZ}\right]^{ \pm}$, dissociation of which forms the cracked products. The apparent reaction rate, $R_{\mathrm{app}}$, conforms to the following expression,

$$
R_{\text {app }}=\frac{k_{\text {int }} K_{\text {ads }} P_{\mathrm{A}}}{\left(1+K_{\text {ads }} P_{\mathrm{A}}\right)},
$$

where $k_{\text {int }}$ is the intrinsic rate constant, $K_{\text {ads }}$ is the equilibrium adsorption constant, and $P_{\mathrm{A}}$ is the partial pressure of alkane. Under monomolecular cracking conditions the surface coverage of alkane is low, i.e., $K_{\text {ads }} P_{\mathrm{A}} \ll 1$, thus Eq. (3) reduces to

$R_{\text {app }}=k_{\text {int }} K_{\text {ads }}^{\prime} P_{\mathrm{A}}=k_{\text {app }} P_{\mathrm{A}}$,

where $K_{\text {ads }}^{\prime}$ is Henry's constant. The rate expression, therefore, is first order in hexane partial pressure, and the apparent rate constant is the product of the intrinsic rate constant and the adsorption equilibrium constant. The temperature dependence of the apparent rate constant gives the apparent activation energy ( $E_{\text {app }}$ ), which is equal to the intrinsic activation energy $\left(E_{\text {int }}\right)$ plus the heat of alkane adsorption $\left(\Delta H_{\text {ads }}\right)[26]$.

$E_{\text {app }}=E_{\text {int }}+\Delta H_{\text {ads }}$.

Several studies have successfully interpreted the differences in apparent rates as being due to the differences in heats of adsorption and surface coverage of alkane. For example, in MFI the cracking rate on $n$-alkanes increases and the apparent activation energy decreases as the molecular weight increases [25,27]. It was suggested that for larger $n$ alkanes the increased heat of adsorption leads to a higher surface coverage and an increased rate. After correcting for the adsorption enthalpy, and therefore the increased surface coverage, the intrinsic rate constant for all $n$-alkanes was identical. Similarly, the difference in apparent reaction rate for $n$-alkane cracking [28] and paraffin isomerization [29] by different zeolites was suggested to be due primarily to the enthalpies of adsorption, rather than due to changes in the intrinsic acid strength of the zeolites. Likewise, the enhanced activity for alkane cracking over zeolite mordenite was explained in terms of increased sorption of the reactant in the pores of the steamed zeolite [30].

In this study, the apparent monomolecular $n$-hexane cracking rate has been determined for a series of H-ZSM5, H-MOR, and H-USY zeolites modified by changing the $\mathrm{Si} / \mathrm{Al}$ ratio, mild steam dealumination, or different levels of $\mathrm{Na}$ exchange. The changes in the apparent rate constants are consistent with those in the literature. Additionally, the apparent activation energy has been determined and despite the vastly different reaction rates all fall on a single compensation plot with the natural $\log$ of the preexponential factor. The finding of a compensation plot suggests a correlation between the enthalpy and the entropy of adsorption. The linear compensation relation implies that the intrinsic acid strength in all catalysts is very similar. This interpretation implies that the differences in apparent rate of $n$-hexane conversion 
and apparent activation energy are primarily due to differences in the sorption properties, which are affected by pore size, $\mathrm{Si} / \mathrm{Al}$ ratio, $\mathrm{NF} \mathrm{Al}$, and alkali ions, especially at low surface coverage.

\section{Experimental}

\subsection{Zeolite samples and modifications}

H-ZSM-5 (CBV $x$ 20) samples were obtained from Zeolyst with $x$ being the nominal $\mathrm{SiO}_{2} / \mathrm{Al}_{2} \mathrm{O}_{3}$ ratio. The aluminum elemental analysis was determined by ICP and is given in Table 1. CBV5020 was partially dealuminated by steaming for $3 \mathrm{~h}$ at $811 \mathrm{~K}$ with a $\mathrm{H}_{2} \mathrm{O}$ partial pressure of (y) Torr (St-H-ZSM-5 $(y))$. The two large-crystal H-ZSM5 (large crystal) samples with different amounts of aluminum were synthesized in our laboratories and have wellformed crystals of ca. $10 \mu \mathrm{m}$ compared to $0.1-0.5 \mu \mathrm{m}$ for the CBV $x 20$ series. The H-MOR (CBV-30) was a commercial sample with $2.6 \mathrm{wt} \%$ aluminum obtained from Zeolyst. St$\mathrm{H}-\mathrm{MOR}$ was steamed at $673 \mathrm{~K}$ for $3 \mathrm{~h}$ at a $\mathrm{H}_{2} \mathrm{O}$ partial pressure of $40 \mathrm{kPa}$ [30]. A mordenite free of Lewis acid sites and nonframework Al, denoted as MOR (No LS), was obtained by repeated ion exchange (with $1 \mathrm{M} \mathrm{NH}_{4} \mathrm{NO}_{3}$ ) of NaMOR (LZM-5 obtained from UOP) and calcination. $\left(\mathrm{NH}_{4}\right)_{2} \mathrm{SiF}_{6}$ chemically dealuminated $\mathrm{Y}$ (CDHY) was obtained from UOP (LZY-210). The catalyst was ion-exchanged with $1 \mathrm{M}$ $\mathrm{NH}_{4} \mathrm{NO}_{3}$ at $353 \mathrm{~K}$ to remove the residual $\mathrm{Na}$. To preserve the

Table 1

Zeolite samples, elemental analysis, and number of acid sites

\begin{tabular}{lrccc}
\hline Sample & $\begin{array}{r}\text { Al } \\
(\%)\end{array}$ & $\begin{array}{c}\text { Framework } \\
\text { Si/AlF }\end{array}$ & Na/AlF & $\begin{array}{c}\mathrm{H}^{+\mathrm{c}, \mathrm{d}} \\
(\mathrm{mmol} / \mathrm{g})\end{array}$ \\
\hline CDHY & 6.2 & 6.7 & 0.01 & 2.2 \\
H-USY-1 & 12.9 & 6.1 & 0.02 & 2.3 \\
H-USY (no Na) & $(12.9)$ & 6.1 & 0.00 & 2.3 \\
(H, Na)-USY (0.05) & $(12.9)$ & 6.1 & 0.05 & 2.2 \\
(H, Na)-USY (0.12) & $(12.9)$ & 6.1 & 0.12 & 2.1 \\
(H, Na)-USY (0.20) & $(12.9)$ & 6.1 & 0.20 & 1.9 \\
H-MOR & 2.6 & 18 & 0.04 & 0.67 \\
St-H-MOR & 2.6 & 21 & 0.04 & 0.60 \\
H-ZSM-5 (3020) & 2.3 & 18 & 0.01 & 0.85 \\
H-ZSM-5 (5020) & 1.7 & 28 & 0.02 & 0.56 \\
H-ZSM-5 (8020) & 1.1 & 47 & 0.01 & 0.41 \\
H-ZSM-5 (15020) & 0.5 & 94 & 0.01 & 0.19 \\
H-ZSM-5 (lg.xtal) & 0.5 & 107 & 0.01 & 0.19 \\
H-ZSM-5 (lg.xtal) & 1.0 & 56 & 0.01 & 0.37 \\
St-H-ZSM-5 (25) & 1.7 & 32 & 0.02 & 0.50 \\
St-H-ZSM-5 (75) & 1.7 & 32 & 0.02 & 0.40 \\
St-H-ZSM-5 (150) & 1.7 & 45 & 0.02 & 0.30 \\
St-H-ZSM-5 (250) & 1.7 & 53 & 0.02 & 0.21 \\
\hline
\end{tabular}

${ }^{a}$ Determined by a combination of wet chemical analysis and the fraction of Td aluminum by ${ }^{27} \mathrm{Al}$ MAS NMR.

b Sodium determined by wet chemical analysis.

c The number of Brønsted acid sites was determined by $\mathrm{NH}_{3}$ TPD.

d The number of Brønsted acid sites was assumed to be equivalent to number of acid sites by $\mathrm{NH}_{3}$ TPD minus the sodium content. structure of this zeolite, it was converted to the $\mathrm{H}$-form in situ in dry $\mathrm{N}_{2}$, immediately prior to each experiment. H-USY was obtained as $\mathrm{NH}_{4}$-USY (UOP, LZY-84). The amount of $\mathrm{Na}$ was adjusted by ion exchange with $1 \mathrm{M} \mathrm{NH}_{4} \mathrm{NO}_{3}(\mathrm{H}-$ USY-2) or limited amounts of $\mathrm{NaNO}_{3}(\mathrm{H}, \mathrm{Na})$-USY $(x \%$ $\mathrm{Na}$ ). The USY samples were precalcined, ex situ, at $723 \mathrm{~K}$.

The number of Brønsted sites was determined by temperature-programmed desorption (TPD) of $\mathrm{NH}_{4}{ }^{+}$-exchanged zeolites and dried at $375 \mathrm{~K}$. In the TPD of $\mathrm{NH}_{4}{ }^{+}$zeolites, there is no low-temperature peak characteristic with $\mathrm{NH}_{3}$ TPD. $\mathrm{NH}_{4}{ }^{+}$ions do not exchange with Lewis acid sites. For MFI and MOR, the number of acid sites was determined by the amount of $\mathrm{NH}_{3}$ desorbed from an $\mathrm{NH}_{4}{ }^{+}$-exchanged zeolite and is given in Table 1. For Y zeolite, the zeolites were saturated with a flow of $4 \% \mathrm{NH}_{3}$ in He. The catalyst was washed with water and dried at $375 \mathrm{~K}$. The method gave identical results as the $\mathrm{NH}_{4}{ }^{+}$with MFI and did not alter the alkali level in Y. The total number of acid sites in Y zeolite was determined by a combination of TDP and ICP chemical analysis, the number of acid sites from TPD minus the number moles of $\mathrm{Na}$, and is given in Table 1 .

\section{2. n-Hexane cracking}

Monomolecular cracking of $n$-hexane was conducted in a small fixed-bed, plug-flow reactor at atmospheric pressure [28]. Trace olefins were removed from the $n$-hexane passing the feed through concentrated sulfuric acid followed by low-temperature adsorption on H-USY. The $n$-hexane also contained $1600 \mathrm{ppm}$ 2- and 3-methylpentane and 3300 ppm methylcyclopentane. Approximately $10-50 \mathrm{mg}$ of zeolite was pretreated by heating to $833 \mathrm{~K}$ for $1 \mathrm{~h}$ in a flow of dry $\mathrm{N}_{2}$. The ramp rate was $10 \mathrm{~K} / \mathrm{min}$ for the USY and ZSM$5,7.5 \mathrm{~K} / \mathrm{min}$ for MOR samples, and $2 \mathrm{~K} / \mathrm{min}$ for CDHY (chemically dealuminated). Using a slower ramping rate for the USY, ZSM-5, and MOR samples did not have a noticeable effect on the conversion of the catalysts. The moisture content of each zeolite was determined by TGA prior to the experiment. After cooling to the reaction temperature, a stream of hexane in $\mathrm{N}_{2}$ between 0.085 and $0.11 \mathrm{kPa}$ was introduced. The hydrocarbon products were analyzed by online gas chromatography, while $\mathrm{H}_{2}$ was not detected. The selectivity was determined by extrapolation to $0 \% n$-hexane conversion. Activity tests conducted for up to $6 \mathrm{~h}$ showed no deactivation. The conversion was varied by changing the WHSV and maintained below about $25 \%$. The apparent activation energy was determined at temperatures between 750 and $815 \mathrm{~K}$.

\section{3. $n$-Alkane adsorption in $H-M O R$}

The gravimetric and calorimetric alkane adsorption measurements were performed in a modified SETARAM TGDSC 111 instrument. MOR (No LS), H-MOR, and St-HMOR were dried under vacuum at $673 \mathrm{~K}$ for $1 \mathrm{~h}$ and cooled to $323 \mathrm{~K}$. Subsequently, the alkanes $\left(\mathrm{C}_{3}-\mathrm{C}_{6}\right)$ were dosed 
Table 2

$n$-Hexane cracking selectivity extrapolated to $0 \%$ conversion and comparison with literature values

\begin{tabular}{|c|c|c|c|c|c|c|c|c|c|}
\hline \multirow[t]{2}{*}{ Sample } & \multicolumn{9}{|c|}{ Product $^{\mathrm{a}}(\mathrm{mol} \%)$} \\
\hline & $\mathrm{CH}_{4}$ & $\mathrm{C}_{2} \mathrm{H}_{6}$ & $\mathrm{C}_{2} \mathrm{H}_{4}$ & $\mathrm{C}_{3} \mathrm{H}_{8}$ & $\mathrm{C}_{3} \mathrm{H}_{6}$ & $i-\mathrm{C}_{4} \mathrm{H}_{10}$ & $n-\mathrm{C}_{4} \mathrm{H}_{10}$ & $\mathrm{C}_{4} \mathrm{H}_{8}{ }^{\mathrm{b}}$ & $i-\mathrm{C}_{5} \mathrm{H}_{12}$ \\
\hline CDHY & 8 & 14 & 7 & 13 & 40 & 0 & 3 & 14 & 1 \\
\hline H-USY & 8 & 14 & 5 & 13 & 38 & 0 & 4 & 16 & 3 \\
\hline H-USY (0.00) & 6 & 10 & 9 & 8 & 51 & 0 & 3 & 11 & 2 \\
\hline (H, Na)-USY (0.05) & 6 & 10 & 8 & 8 & 48 & 0 & 3 & 12 & 3 \\
\hline$(\mathrm{H}, \mathrm{Na})-\mathrm{USY}(0.12)$ & 7 & 10 & 8 & 8 & 46 & 0 & 4 & 13 & 4 \\
\hline$(\mathrm{H}, \mathrm{Na})-\mathrm{USY}(0.20)$ & 6 & 10 & 8 & 8 & 48 & 0 & 3 & 13 & 5 \\
\hline H-MOR & 6 & 15 & 4 & 12 & 38 & 0 & 2 & 19 & 4 \\
\hline St-H-MOR & 7 & 11 & 8 & 8 & 36 & 0 & 2 & 14 & 1 \\
\hline H-ZSM-5 (5020) & 5 & 16 & 6 & 14 & 36 & 0 & 2 & 20 & 1 \\
\hline St-H-ZSM-5 (25) & 6 & 16 & 3 & 14 & 38 & 0 & 2 & 17 & 1 \\
\hline Average & 7 & 14 & 7 & 12 & 38 & - & 3 & 17 & 2 \\
\hline \multicolumn{10}{|l|}{ Literature } \\
\hline H-ZSM-5 ${ }^{\mathrm{c}}$ & 4 & 17 & 7 & 18 & 34 & - & 4 & 17 & - \\
\hline Deal HY & 3 & 9 & 4 & 24 & 43 & - & 4 & 9 & - \\
\hline $\mathrm{H}-\beta^{\mathrm{c}}$ & - & 4 & 3 & 38 & 47 & - & 3 & 4 & - \\
\hline H-ZSM-5 ${ }^{\mathrm{d}}$ & 5 & 16 & 8 & 13 & 36 & - & 4 & 17 & 2 \\
\hline
\end{tabular}

a Hydrogen was not detected.

b All butene isomers.

c S. Kotrel, M.P. Rosynek, J.H. Lunsford, J. Phys. Chem. B 103 (1999) 818.

d T.F. Narbeshuber, A. Brait, K. Seshan, J.A. Lercher, J. Catal. 172 (1997) 127.

and equilibrated with the surface. When no changes in heat flow and uptake were observed, equilibrium was assumed. The adsorption isotherms were determined gravimetrically together with the differential enthalpies of adsorption. The equilibrium adsorption constants calculated from the Langmuir equation and the measured enthalpies were used to calculate the entropy of adsorption.

\section{Results}

The $n$-hexane cracking selectivities at $773 \mathrm{~K}$ extrapolated to $0 \%$ conversion are given in Table 2 . Within the experimental uncertainties, the product distributions are identical for all zeolites and are consistent with those previously reported for monomolecular cracking of $n$-hexane, which are also given in Table 2 [25,31]. For the monomolecular pathway, the primary product of protolysis gives unity molar ratio of methane versus pentene, $\mathrm{C}_{2}$ versus $\mathrm{C}_{4}$ (either ethylene plus butane or ethane and butene), propane versus propene, and hydrogen versus hexene. The high olefin to paraffin ratio, the low selectivity to iso-pentane and iso-butane, and the absence of detectable $\mathrm{C}_{7}$. products are consistent with the absence of the bimolecular cracking pathway. However, in general the molar ratios are also not consistent with a simple monomolecular cracking pathway where only the primary products are formed. For example, the propene to propane ratio is greater than one, and although there are significant amounts of methane, there is no pentene.

The absences of pentene (and hexene) indicate that these larger olefins rapidly undergo secondary cracking reactions. Thus, cracking of these primary olefin products would produce two smaller olefin products. For pentene, the products would be ethene and propene in equal molar amounts. For $7 \mathrm{~mol} \%$ methane, the equivalent amount of pentene would give $7 \mathrm{~mol} \%$ of ethene and propene. Since this is nearly identical to the ethene selectivity, this suggests that little ethene forms as a primary cracking product, i.e., the reaction to give ethene plus $n$-butane. The low $n$-butane selectivity is consistent with this conclusion. Therefore, a large fraction of the $\mathrm{C}_{2}$ plus $\mathrm{C}_{4}$ products is butene plus ethane in equal molar amounts. Secondary cracking of hexene might also be expected to give two sets of products, $2 \mathrm{~mol}$ of propene, and ethene plus butene. However, since the butene/ethane ratio is close to one and the moles of ethene is that expected from secondary cracking of pentene, it is likely that secondary cracking of hexene predominantly forms propene.

The propene selectivity is about $38 \%$ and is much larger than that of propane (12\%) and expected as a primary cracking product. It is too large even after accounting for the amount formed by secondary cracking of pentene. Accounting for the amount of propylene formed as a primary product and a secondary product from pentene, the amount of excess propene is $19 \%$, i.e., 38-12-7. This is presumed to be formed by secondary cracking of hexene. Thus, greater than $95 \%$ of the reaction products can be accounted for by the following monomolecular cracking for $n$-hexane:

$$
\begin{aligned}
& n-\mathrm{C}_{6} \mathrm{H}_{14} \rightarrow \mathrm{H}_{2}+n-\mathrm{C}_{6} \mathrm{H}_{12} \rightarrow \mathrm{H}_{2}+2 \mathrm{C}_{3} \mathrm{H}_{6}, \\
& n-\mathrm{C}_{6} \mathrm{H}_{14} \rightarrow \mathrm{CH}_{4}+n-\mathrm{C}_{5} \mathrm{H}_{10} \rightarrow \mathrm{CH}_{4}+\mathrm{C}_{2} \mathrm{H}_{4}+\mathrm{C}_{3} \mathrm{H}_{6}, \\
& n-\mathrm{C}_{6} \mathrm{H}_{14} \rightarrow \mathrm{C}_{2} \mathrm{H}_{6}+n-\mathrm{C}_{4} \mathrm{H}_{8}, \\
& n-\mathrm{C}_{6} \mathrm{H}_{14} \rightarrow \mathrm{C}_{3} \mathrm{H}_{8}+\mathrm{C}_{3} \mathrm{H}_{6} .
\end{aligned}
$$

Although several additional reactions (e) and (f) are possible, these do not appear to contribute significantly to the 
Table 3

Kinetic parameters, apparent rate constant at $773 \mathrm{~K}$, apparent activation energy, and preexponential factor for monomolecular cracking of $n$-hexane

\begin{tabular}{lrcc}
\hline Sample & $k_{\text {app }}{ }^{\mathrm{a}}$ & $A_{\text {app }}{ }^{\mathrm{b}}$ & $E_{\text {app }}{ }^{\mathrm{c}}$ \\
\hline CDHY & 690 & $6.8 \times 10^{15}$ & 186 \\
H-USY-1 & 990 & $2.5 \times 10^{15}$ & 178 \\
H-MOR & 1500 & $3.1 \times 10^{14}$ & 157 \\
St-H-MOR & 7400 & $8.9 \times 10^{14}$ & 153 \\
H-ZSM-5 (3020) & 2900 & $6.2 \times 10^{11}$ & 108 \\
H-ZSM-5 (5020) & 3000 & $5.0 \times 10^{12}$ & 124 \\
H-ZSM-5 (8020) & 2700 & $2.1 \times 10^{11}$ & 106 \\
H-ZSM-5 (15020) & 2200 & $5.3 \times 10^{10}$ & 100 \\
H-ZSM-5 (lg.xtal) & 1600 & $7.3 \times 10^{11}$ & 122 \\
H-ZSM-5 (lg.xtal) & 2600 & $2.6 \times 10^{11}$ & 107 \\
St-H-ZSM-5 (25) & 6100 & $9.2 \times 10^{12}$ & 124 \\
St-H-ZSM-5 (75) & 4800 & $1.2 \times 10^{12}$ & 114 \\
St-H-ZSM-5 (150) & 1200 & $7.3 \times 10^{12}$ & 122 \\
St-H-ZSM-5 (250) & 2600 & $2.2 \times 10^{12}$ & 128 \\
\hline
\end{tabular}

a Apparent rate constant at $773 \mathrm{~K}$ with units $[\mu \mathrm{mol}$ mol Brønsted sites ${ }^{-1} \mathrm{~s}^{-1} \mathrm{kPa}^{-1}$ ] based on the number of catalytic sites in USY determined from Fig. 1.

b Preexponential factor with units of [molecules Brønsted site ${ }^{-1} \mathrm{~s}^{-1}$ $\left.\mathrm{kPa}^{-1}\right]$.

${ }^{c}$ Estimated error is $\pm 9 \mathrm{~kJ} / \mathrm{mol}$.

reaction products:

$n-\mathrm{C}_{6} \mathrm{H}_{14} \rightarrow \mathrm{H}_{2}+n-\mathrm{C}_{6} \mathrm{H}_{12} \rightarrow \mathrm{H}_{2}+\mathrm{C}_{2} \mathrm{H}_{4}+\mathrm{C}_{4} \mathrm{H}_{8}$,

$n-\mathrm{C}_{6} \mathrm{H}_{14} \rightarrow \mathrm{C}_{2} \mathrm{H}_{4}+n-\mathrm{C}_{4} \mathrm{H}_{10}$.

If reactions (a)-(d) are assumed to be the only reactions that contribute to the products, the selectivity is well reproduced assuming that the relative rates are approximately $3: 2: 2: 4$, respectively. This analysis of the cracking reactions is in good agreement with those previously made for the monomolecular cracking pathway for $n$-hexane [25,28,31].

\subsection{Kinetic parameters}

Under the reaction conditions employed in this study, the product selectivity did not change with time on stream, the conversion was independent of the sequence of experiments, and the catalysts did not deactivate. The apparent kinetic parameters (apparent rate constant at $773 \mathrm{~K}$, apparent activation energy and preexponential factor) are given in Table 3.

Ion exchange of Brønsted sites by $\mathrm{Na}^{+}$ions in $\mathrm{Y}$ zeolite leads to a decrease in conversion. Consistent with previous studies of alkali poisoning, the activity declines at a faster rate than can be accounted for by the loss of acid sites $[2,32]$. For example, a loss of $12 \%$ of the acid sites $\left(\mathrm{Na} / \mathrm{Al}_{\mathrm{F}}=0.12\right)$ leads to of $45 \%$ loss in activity, i.e., $k_{\text {app }}$ decreases from 300 to $170 \mu \mathrm{mol}$ mol Brønsted sites ${ }^{-1} \mathrm{~s}^{-1} \mathrm{kPa}^{-1}$. In Fig. 1, there is a linear decrease in the apparent rate constant with increasing alkali. Extrapolation to zero conversion, i.e., an apparent rate constant of zero, indicates that about two-thirds of the acid sites do not contribute to conversion, implying that only one-third of the acid sites are exposed to the reactants $[33,34]$. Based on Fig. 1, the rate constant for Y zeolite

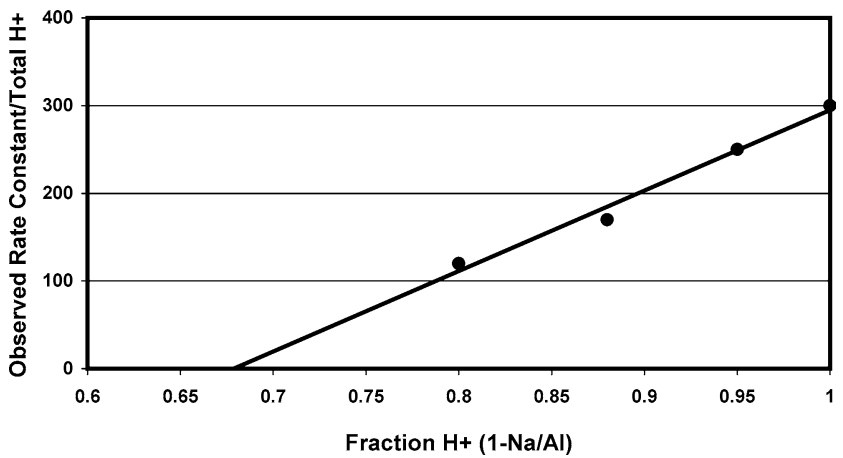

Fig. 1. The effect of the addition of alkali on the apparent rate constant for $n$-hexane conversion over USY zeolite.

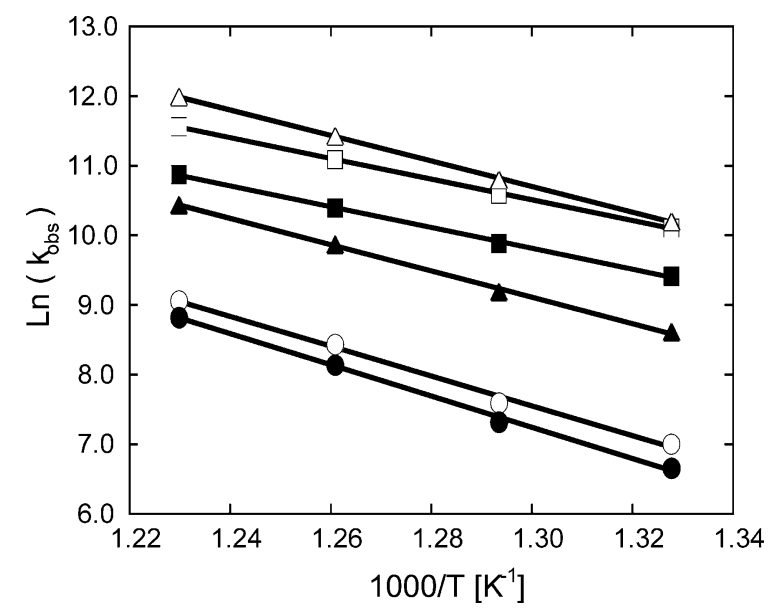

Fig. 2. Arrhenius plot for monomolecular $n$-hexane cracking over H-USY

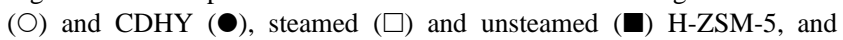
steamed $(\triangle)$ and unsteamed $(\mathbf{\Lambda})$ H-MOR.

was determined assuming the number of catalytic acid sites was one-third the total number of Brønsted sites.

In the absence of steaming, the apparent rate constants increase in the order of structure types $\mathrm{Y}<\mathrm{MOR}<\mathrm{MFI}$ in agreement with previous studies [28,31]. The apparent rate constant of FAU (CDHY) was approximately two times lower than that of H-MOR, which in turn was approximately two times lower than MFI. Within a given structure type, for example, MFI, the apparent rate constants were very similar with different $\mathrm{Si} / \mathrm{Al}$ ratios and crystal sizes. The latter result indicates that the rate of monomolecular $n$-hexane cracking is not influenced by diffusional limitations. Mild steam dealumination at low $\mathrm{H}_{2} \mathrm{O}$ pressure leads to a fivefold increase in the apparent rate constant in MOR and a twofold increase in MFI. With increasing severity of steaming, the apparent rate constant decreases in MFI, indicating that there is an optimum in the activity with steaming. These results are consistent with previous studies on mild steam dealumination of MFI and MOR zeolites [10-17,22,30].

The apparent activation energies and preexponential factors were determined from slope and intercepts of the Arrhenius plots (Fig. 2), respectively, and are given in Table 3. The preexponential values for $\mathrm{Y}$ zeolite were calculated based on 


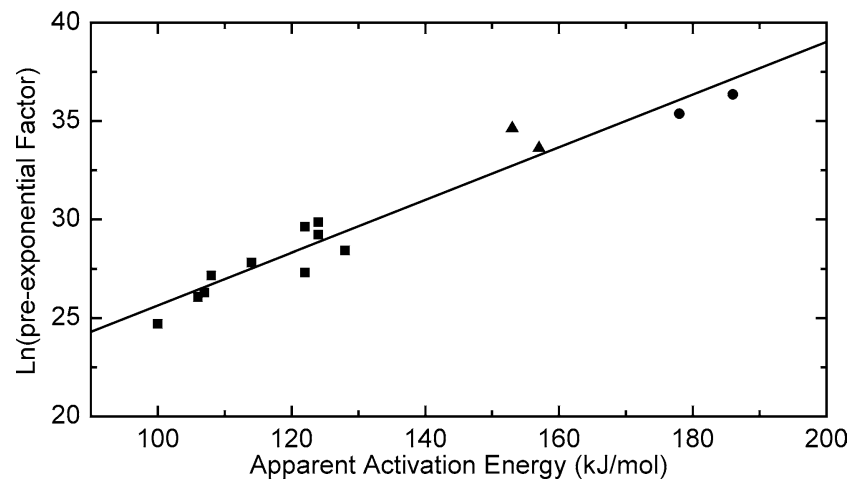

Fig. 3. Compensation plot for monomolecular cracking of $n$-hexane over

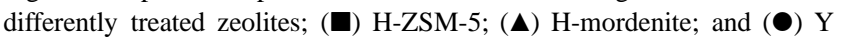
zeolite.

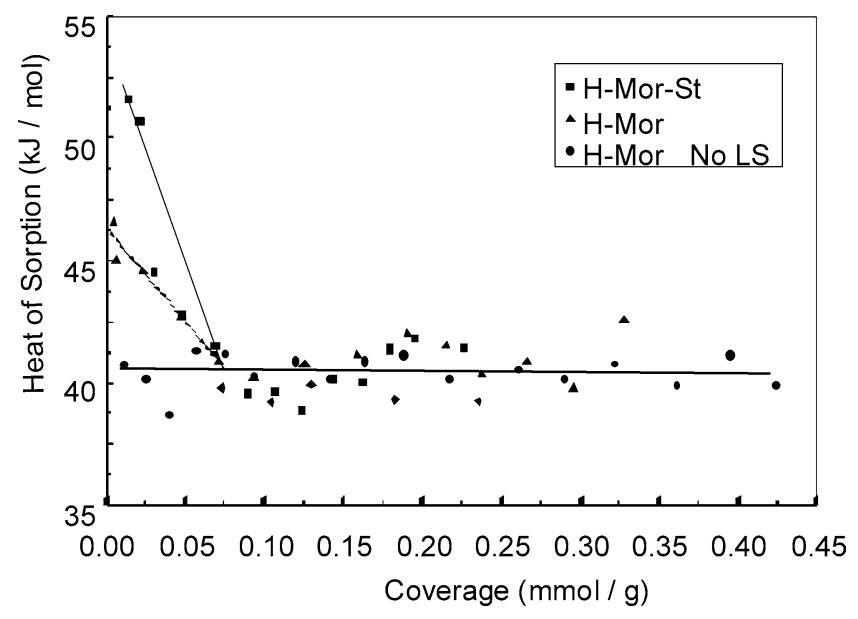

Fig. 4. Coverage dependency of the heat of adsorption of propane on zeo-

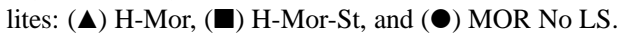

the number of catalytic Brønsted sites. Like the apparent rate constants, the largest deviations occur between zeolites with different structures and within a given structure the differences are smaller. The apparent activation energies decrease in the order $\mathrm{Y}>\mathrm{MOR}>\mathrm{MFI}$. Using the apparent kinetic parameters, a Constable plot, i.e., a plot of the apparent activation energy versus the natural log of the preexponential factor, shows a linear compensation in Fig. 3. The values for all zeolites and modifications within experimental error fall on a single line.

\subsection{Sorption of alkanes in $H-M O R$}

The enthalpy of adsorption with increasing surface coverage was determined for propane, $n$-butane, $n$-pentane, and $n$ hexane on the MOR catalysts and previously published [30]. The surface was considered saturated when there was a sharp decrease in the heat of adsorption with subsequent doses of hydrocarbon. A typical heat of adsorption plot is shown in Fig. 4. This figure shows the heat of adsorption as function of coverage of propane on samples H-MOR, H-MOR-St, and MOR (No LS). The sample free of Lewis acid sites shows a constant heat of adsorption for all coverages, in con-

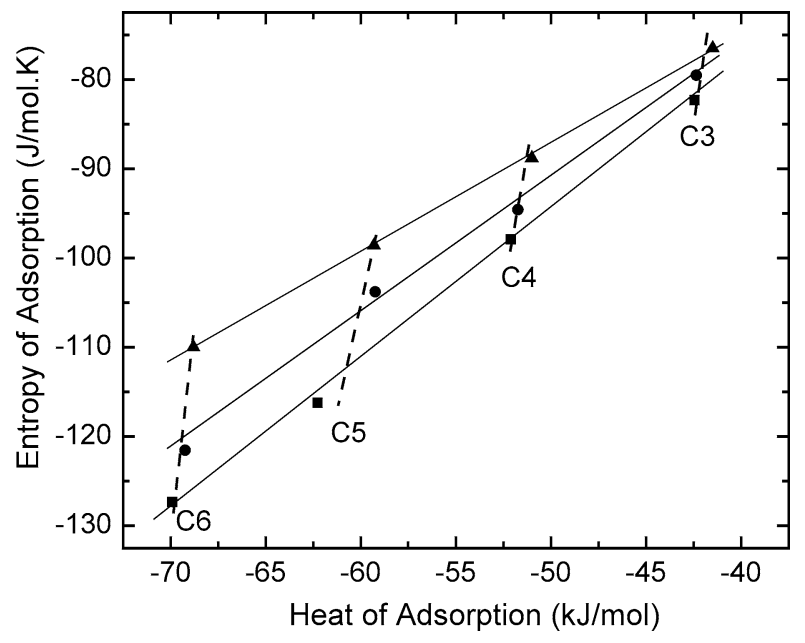

Fig. 5. Correlation between the enthalpies and entropies of alkane sorption in H-mordenite: (A) NF Al and Lewis acid free H-Mor; (O) H-Mor; St-H-Mor.

trast to samples H-MOR and H-MOR-St that show enhanced heats of adsorption at coverages lower than $0.1 \mathrm{mmol} / \mathrm{g}$. HMOR-St clearly shows a higher heat of adsorption at low coverages compared to H-Mor. At coverages higher than $0.1 \mathrm{mmol} / \mathrm{g}, \mathrm{H}-\mathrm{MOR}$ and H-MOR-St show identical heats of adsorption as the sample free of Lewis acid sites. With increasing amounts of NF Al the initial heat of adsorption increased by $5-15 \mathrm{~kJ} / \mathrm{mol}$. The number of these more strongly adsorbing sites is about $5-10 \%$ of the saturation adsorption capacity. The sites that show enhanced heats of adsorption are ascribed to Lewis acid sites formed during the dealumination procedures [30].

The heat of adsorption increases as the molecular weight of the alkane increases [30]. For mordenite, the enthalpy increases by about $10 \mathrm{~kJ} / \mathrm{mol}$ per $-\mathrm{CH}_{2}-$ group due to the increased interaction of alkane with the pore wall. Adsorption isotherms at $323 \mathrm{~K}$ were obtained for each alkane and fit to the Langmuir equation for calculation of the adsorption equilibrium constant. From the equilibrium constant and the integral enthalpy of adsorption, the entropy of adsorption was calculated. The integral enthalpy term was determined by averaging the heats of adsorption at saturation coverage. Fig. 5 shows that there is a linear correlation between the entropy and the integral enthalpy of adsorption. The dashed lines represent the different alkanes. The solid lines represent the different MOR catalysts (H-MOR, St-H-MOR, and an MOR No LS). Although the integral heat of adsorption increases with the molecular weight with about $10 \mathrm{~kJ} / \mathrm{mol}$ per $-\mathrm{CH}_{2}-$ group for each zeolite, for a given hydrocarbon, it is not identical for each zeolite. There are variations due to the different treatments resulting from contributions to the enthalpy of adsorption on Lewis acid sites in the zeolite pores at low coverage [30] (Fig. 4). Although there is only a small change in the number of strongly adsorbing sites, this leads to a significant effect on the entropy of adsorption; i.e., the higher the heat of adsorption the greater the loss in entropy. 


\section{Discussion}

\subsection{Sorption of alkanes in zeolites}

The interaction of an alkane with a zeolite is dominated by two factors. The first is the van der Waals interaction, which accounts for the pore-wall alkane interaction. The second is the dipole-induced hydrogen bonding with the Brønsted acid site [35-40]. The second term constitutes a constant value, which is around $10 \mathrm{~kJ} / \mathrm{mol}$. The first term dominates the interaction and is larger for longer alkanes; each adjoined $-\mathrm{CH}_{2}-$ group contributes a nearly constant amount of heat (Fig. 5).

The pore size strongly affects the enthalpy of adsorption and is higher for smaller pore zeolites. This is known as the confinement effect $[36,38]$. For example, the enthalpy of $n$-hexane adsorption in H-ZSM-5 is about $86 \mathrm{~kJ} / \mathrm{mol}$, but decreases to 69 and $50 \mathrm{~kJ} / \mathrm{mol}$ in MOR and H-Y, respectively [28]. In addition to pore size, the enthalpy of adsorption is altered by the presence of ions in the pores, for example, NF Al. In Fig. 4, it can be seen that at low surface coverage the initial heat of adsorption for propane is greater than that at saturation coverage. The enthalpies of adsorption on these initial alkane adsorption sites are $5-15 \mathrm{~kJ} / \mathrm{mol}$ higher than the interaction with the pore walls and Brønsted acid sites. This is also reflected in the higher integral heats of adsorption for $n$-butane, $n$-pentane, and $n$-hexane in Fig. 5.

\subsection{Effect of adsorption on the apparent reaction rate and activation energy}

As outlined in Eqs. (1)-(5), a Langmuir-Hinshelwood model adequately describes the kinetics of monomolecular alkane cracking in zeolites. The reaction is first order in reactant and the apparent rate constant, $k_{\mathrm{app}}$, is the product of the adsorption equilibrium constant, $K_{\mathrm{ads}}$, and the intrinsic rate constant, $k_{\text {int }}$ [Eq. (4)]. Thus, in order to determine the effect of acid strength on the cracking rate of zeolites, for example, it is also necessary to account for the differences in surface coverage due to differences in thermodynamics of adsorption. Since both the intrinsic rate constant and the adsorption equilibrium constant have the same temperature dependency, the apparent activation energy has two contributions, $E_{\text {int }}$ and $\Delta H_{\text {ads }}$ [Eq. (5)]. Recently, several studies have recognized the significance of adsorption on the apparent cracking rates and apparent activation energies in zeolites [25,27,28, 30,41] (Table 4).

The apparent rate of $n$-alkane cracking over H-ZSM-5 increases as the length of the alkane increases [25,27,41]. In addition, the apparent activation energy decreases with increasing carbon number. After correction for the heats of alkane adsorption, the intrinsic activation energy was nearly identical for each reactant. The differences in the apparent rates of reaction are entirely determined by differences in surface coverage as a consequence of $K_{\text {ads }}$, which is larger
Table 4

Summary of apparent and intrinsic kinetic parameters of monomolecular cracking of alkanes over zeolites

\begin{tabular}{|c|c|c|c|}
\hline & $\begin{array}{l}\text { Relative } \\
\text { activity }\end{array}$ & $\begin{array}{c}E_{\text {app }} \\
(\mathrm{kJ} / \mathrm{mol})\end{array}$ & $\begin{array}{c}E_{\text {true }} \\
(\mathrm{kJ} / \mathrm{mol})\end{array}$ \\
\hline \multicolumn{4}{|c|}{ Compensation plot of data presented $^{\mathrm{a}}$ [27] } \\
\hline Butane & - & 142 & 205 \\
\hline Hexane & - & 126 & 205 \\
\hline Octane & - & 92 & 197 \\
\hline Nonane & - & 84 & 197 \\
\hline Decane & - & 67 & 193 \\
\hline \multicolumn{4}{|c|}{ Compensation plot constructed in this paper ${ }^{\mathrm{b}}[25]$} \\
\hline Propane & 1 & 155 & 198 \\
\hline Butane & 6.5 & 135 & 197 \\
\hline Pentane & 34 & 120 & 194 \\
\hline Hexane & 114 & 105 & 197 \\
\hline \multicolumn{4}{|c|}{ Refs. $[43,44]^{\mathrm{c}}$} \\
\hline Propane & 1 & 165 & 191 \\
\hline Butane & $8^{\mathrm{d}}$ & 140 & 175 \\
\hline Pentane & 70 & 135 & 183 \\
\hline \multicolumn{4}{|c|}{$\begin{array}{c}\text { Compensation plot constructed in this paper, } \\
\text { including additional data } \mathrm{e}^{\mathrm{e}}[28]\end{array}$} \\
\hline H-ZSM-5 & 14 & 149 & 235 \\
\hline H-MOR & 6.5 & 157 & 226 \\
\hline $\mathrm{H}-\mathrm{Y}$ & 1 & 186 & 236 \\
\hline $\begin{array}{l}\text { Ref. }[41]^{f} \\
\text { Constant il }\end{array}$ & activity & nol & \\
\hline
\end{tabular}

a H-ZSM-5, 1 bar total pressure, low pP alkane.

b $\mathrm{H}$-ZSM-5, 1 bar total pressure, $0.1<\mathrm{pP}$ alkane $<10 \mathrm{kPa}$.

c H-FAU, 1 bar total pressure, $0.1<\mathrm{pP}$ alkane $<10 \mathrm{kPa}$.

$\mathrm{d}$ Secondary reactions are observed, see text for details.

e $n$-Hexane, 1 bar total pressure, $87<\mathrm{pP}$ alkane $<380 \mathrm{~Pa}$.

f $\mathrm{H}-\mathrm{ZSM}-5$, propane to eicosane.

for the higher molecular weight alkanes. The authors concluded that a higher cracking rate does not imply that the longer paraffins are more reactive, i.e., have a larger $k_{\text {int }}$, but that they have a larger $K_{\text {ads }}$.

Very similar conclusions were drawn for hydro-isomerization of alkanes of different chain lengths. As the length of the alkane increases, the reactivity (conversion) of the paraffin increases and the differences in activity are governed by their physisorption properties [29,42]. Likewise, the hydroisomerization activity of $n$-hexane over acid-extracted and steamed MOR may be accounted for by changes in the sorption enthalpies [30]. These studies conclude that the higher isomerization rates are due to the increased concentration of reactants within the pores, rather than due to differences in the reactivity of the paraffins or the strength of the acid sites.

As observed for H-ZSM-5, the apparent activation energies ( $\left.E_{\text {app }}\right)$ for propane, butane, and pentane cracking over zeolite FAU decrease with increasing carbon number (Table 4) $[43,44]$. After correction for the heats of adsorption, not only are the intrinsic activation energies for propane and pentane nearly identical, but also they are very similar to those in H-ZSM-5, implying that the acid strength of Brønsted sites is similar. The intrinsic activation energy for 
$n$-butane was lower, which was ascribed to a significant contribution from bimolecular reactions to the conversion [44].

Table 4 also contains results for the monomolecular cracking of $n$-hexane on H-ZSM-5, H-MOR, and H-Y. Under equivalent reaction conditions, the reaction rate increases as the pore size decreases, i.e., H-ZSM-5 > MOR > Y. In addition, the apparent activation energy decreased in the same order; the zeolite with the highest activity had the lowest apparent activation energy. After correction for the enthalpies of adsorption [Eq. (5)], the intrinsic activation energies of the zeolites with different structure were similar and lead the authors to conclude that despite the different cracking conversions, the intrinsic acid strength in the different zeolites was very similar [28]. In this study, zeolites of the same structure were assumed to have the same enthalpy of adsorption, taken from values reported in the literature, which is an oversimplification (vide infra).

Similar to previous studies, mild steam dealumination of mordenite leads to increased conversion for monomolecular $n$-butane cracking up to a maximum of 2.7 times per Brønsted acid site $[2,3,11,18,30]$. Steam dealumination leads to an increase in the low coverage enthalpy of sorption by about $5-15 \mathrm{~kJ} / \mathrm{mol}$, depending on the degree of dealumination, which was correlated with the increased activity. The amount of NF Al also correlated with the number of Lewis acid sites. It was proposed that MOR with NF Al, i.e., Lewis acid sites formed by mild steaming, has a higher enthalpy of adsorption. These sites are important since under reaction conditions the surface coverage of alkane is low, and a few more energetic adsorption sites significantly increase the fractional coverage. The enhanced conversion due to steaming was proposed to be due to the higher surface coverage of reactants, rather than due to the formation of a highly reactive Brønsted site.

All the above studies indicate that the differences in conversion of alkanes by monomolecular cracking on zeolites are dominated by changes in $K_{\text {ads }}$ and that changes in $k_{\text {int }}$ are smaller and much less important. The sorption preequilibrium controls the concentration of alkanes in the pores of the zeolite [Eq. (1)] and, therefore, the extent of conversion [Eq. (4)]. Although the structure, $\mathrm{Si} / \mathrm{Al}$ ratio, $\mathrm{NF} \mathrm{Al}$, alkali ions, etc., lead to changes in conversion, an increased conversion does not necessarily mean that the strength of the Bronsted site has increased. Finally, a small change in the number of more energetic adsorption sites, especially if they are located next to a Brønsted acid site, can significantly alter the alkane surface coverage and lead to a significant change in conversion.

\subsection{Compensation correlation for monomolecular alkane cracking on ZSM-5}

As discussed above, several studies have established that the intrinsic cracking activation energy of $n$-alkanes of different molecular weight is nearly identical and that the difference in apparent rate is dominated by the difference in

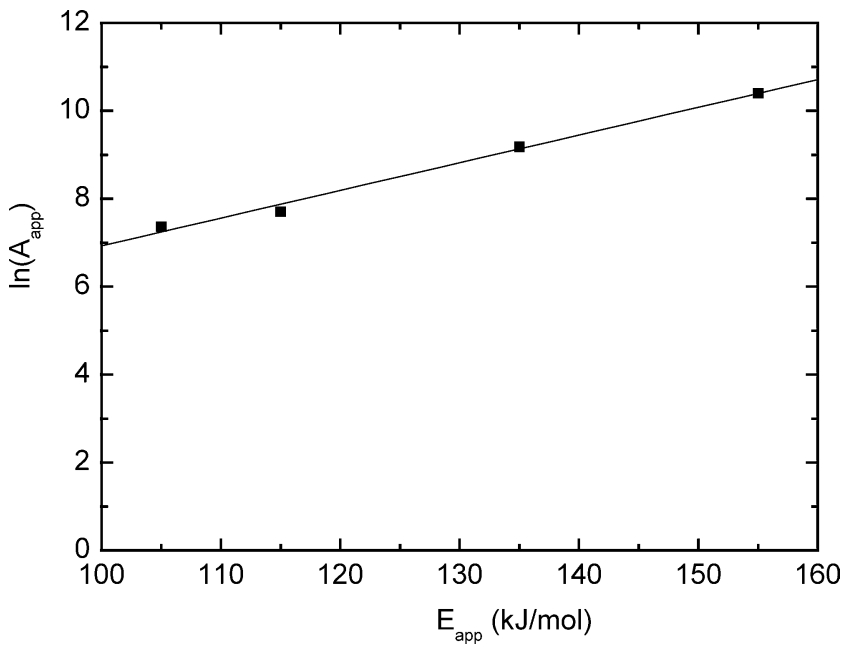

Fig. 6. Compensation (Constable) plot for monomolecular cracking of linear alkanes of various lengths over zeolite H-ZSM-5 (data taken from [25]).

the surface coverage of alkane. The different temperature dependence of surface coverage also leads to a decrease in the apparent activation energy with increasing carbon number [25,27]. Using the reported apparent activation energy and preexponential factors [25], a Constable or compensation plot was constructed and is shown in Fig. 6. The linear correlation coefficient of $R=0.996$ indicates that as the apparent activation energy decreases the natural log of the apparent preexponential factor also decreases. As indicated by Bond [45], a true compensation relation displays an isokinetic point, i.e., extrapolation of the Arrhenius plots intersect at a common temperature. From the reported reaction temperatures, rates of reaction, and the apparent kinetic parameters, the Arrhenius plots were reproduced, Fig. 7a, and the extrapolated isokinetic point is shown in Fig. $7 \mathrm{~b}$. $n$-Alkane cracking in H-ZSM-5 displays a true compensation relation.

While there is no general agreement as to the interpretation of the compensation effect, we make the following interpretation of the temperature dependence of the apparent rate constant:

$k_{\text {app }}=A_{\text {app }} \mathrm{e}^{\left(-E_{\text {app }} / R T\right)}$.

From Eq. (4),

$k_{\text {app }}=K_{\text {ads }} k_{\text {int }}$.

The temperature dependencies of $K_{\text {ads }}$ and $k_{\text {int }}$ are

$K_{\text {ads }}=\mathrm{e}^{\left(-\Delta G_{\text {ads }} / R T\right)}=\mathrm{e}^{\left(-\Delta H_{\text {ads }} / R T\right)} \mathrm{e}^{\left(\Delta S_{\text {ads }} / R\right)}$,

$k_{\text {int }}=A_{\text {int }} \mathrm{e}^{\left(-E_{\text {int }} / R T\right)}$.

Combining Eqs. (6), (8), and (9) leads to the following relations:

$E_{\mathrm{app}}=E_{\mathrm{int}}+\Delta H_{\mathrm{ads}}$,

$\ln A_{\text {app }}=\ln A_{\text {int }}+\frac{\Delta S_{\text {ads }}}{R}$. 

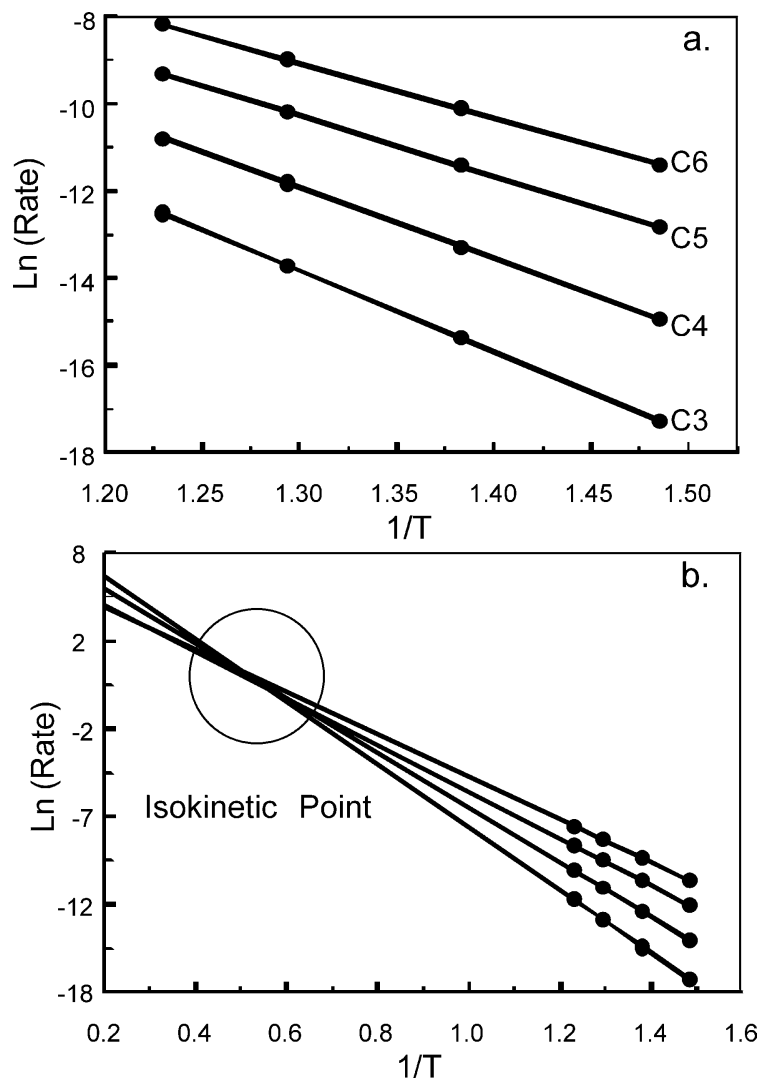

Fig. 7. (a) Arrhenius plots of monomolecular cracking of linear alkanes over zeolite H-ZSM-5 (data taken from Ref. [25]). (b) Extrapolation of the Arrhenius plots indicating an isokinetic temperature.

The compensation plot, therefore, is a correlation between the entropy of adsorption plus the natural log of the intrinsic preexponential factor versus the enthalpy of adsorption plus the intrinsic activation energy. Since for $n$-alkane monomolecular cracking in $\mathrm{H}-\mathrm{ZSM}-5$, the intrinsic terms are constant (Table 4, Fig. 7), the compensation correlation will have the same interdependence as the entropy and enthalpy of adsorption, which has been shown to be linear [40].

\subsection{Implication of a compensation relation for different zeolites}

For monomolecular $n$-hexane cracking with different zeolites and treatments, there is also a linear compensation plot (Fig. 3). However, for these different zeolites there is no implicit reason that the intrinsic kinetic parameters should be identical. In fact, most studies conclude that the intrinsic acid strength, and thus the intrinsic rate constant, of different zeolites is significantly different.

The adsorption equilibrium constant is determined primarily by the van der Waals attraction between the paraffin with the zeolite walls, while the intrinsic rate constant is dependent on the chemical interaction between the alkane and the Brønsted acid site. Thus, the equilibrium adsorption constant and the intrinsic kinetic rate constant correspond to very different fundamental processes involving the alkane, and one would not expect to observe a linear Constable plot if both properties vary quite differently for different zeolites. The apparent compensation effect implies some correlation between the intrinsic kinetic parameters and the entropy and enthalpy of adsorption, as suggested by Eqs. (5) and (10). The two extreme cases correspond to the situation that intrinsic kinetic parameters are identical and the entropy and enthalpy are linearly correlated, or the entropy and enthalpy of adsorption are identical and the intrinsic rate constant and preexponential are linearly correlated. For paraffin cracking on zeolites, several studies have shown that the latter is not true. Therefore, a linear compensation plot may suggest that the intrinsic activation energy and preexponential factors in these zeolites are identical, or at least very similar. Small changes in the acid strength and intrinsic rate constant would cause deviation from a perfectly linear Constable plot. The linear compensation plot for these unrelated zeolites and treatments implies that the intrinsic acid strength of Brønsted sites is very similar, despite the large differences in apparent conversion (per acid site) under reaction conditions. Theoretical calculations have suggested that the intrinsic activation energy for monomolecular cracking is fairly independent of hydrocarbon [46,47].

If the zeolites in Fig. 3 do have similar intrinsic rate constants and activation energies, then the apparent different activities are due to changes in the enthalpies of adsorption. Furthermore, each treatment, for example, leads to a small but significant change in the enthalpy of adsorption. The implication is that each ZSM-5 sample, for example, has a different enthalpy of adsorption, especially at low surface coverage. One possible cause may be the presence of small amounts of Lewis acid sites in some of the samples. Such small changes have been observed on steam-dealuminated MOR where NF Al for Lewis acid sites have a higher heat of adsorption than in the zeolite without these species (Figs. 4 and 5).

The apparent linear Constable plot implies not only that the intrinsic kinetic parameters are identical, but that there is also a linear correlation between the entropy and enthalpy of adsorption for all zeolites including those with different structures. While a linear correlation between the entropy and the enthalpy of adsorption was shown for MOR (Fig. 5), it remains to be demonstrated for all the zeolite structures and treatments. However, as long as the enthalpy of adsorption is dominated by physical adsorption, it seems reasonable that an increase in enthalpy will result in a proportional loss of entropy, i.e., from gas phase to adsorbed phase.

\section{Conclusion}

Monomolecular $n$-hexane cracking over zeolites of different structure types shows large differences in conversion and apparent activity per acid site. The conversion increased in the order H-ZSM-5 > MOR > Y. Smaller variations in conversion were observed for samples of the same structure 
that were modified by the $\mathrm{Si} / \mathrm{Al}$ ratio, steam dealumination, or addition of alkali. Mild steam dealumination initially increased the cracking conversion in H-ZSM-5, but decreased with further dealumination. Similar increases in conversion were obtained for steam dealumination in MOR. Addition of alkali reduced the number of Brønsted sites in Y; however, the cracking rate decreased faster than the loss in the number of acid sites.

Despite the vastly different properties, treatments, and apparent activities of the zeolites, a linear compensation relation is found for monomolecular cracking in a Constable plot. The compensation plot is interpreted by suggesting that the apparent activation energy is equal to the enthalpy of adsorption plus the intrinsic activation energy and that the natural log of the apparent preexponential factor is equal to the entropy of adsorption plus the natural $\log$ of the intrinsic preexponential factor. The linear compensation plot can be interpreted to indicate very similar intrinsic kinetic parameters in each zeolite and that the differences in apparent activity are determined primarily by the alkane surface coverage. Small differences in the low coverage enthalpy of adsorption with increasing amounts on $\mathrm{NF} \mathrm{Al}$, which correlate with an increase in the number of Lewis acid sites and an increase in activity, are observed in steam-dealuminated MOR. A linear Constable relation also suggests that there is a linear dependence between the enthalpy and the entropy of adsorption for all zeolites and treatments. This linear relation between the entropy and the enthalpy of adsorption is observed for steam-dealuminated MOR.

\section{Acknowledgments}

The sorption experiments were performed in the laboratory of professor J.A. Lercher, who is also thanked for fruitful discussions. J.A.vB. thanks the Niels Stensen Stichting, and B.A.W. and H.H.K. the National Science Foundation (CTS-9807333) for financial support.

\section{References}

[1] T. Sie, in: H. Van Bekkum, P.A. Jacobs, E.M. Flanigen, J.C. Jansen (Eds.), Introduction to Zeolite Science and Practice, Elsevier, Amsterdam, 2001.

[2] P.O. Fritz, J.H. Lunsford, J. Catal. 118 (1989) 85.

[3] F. Lónyi, J.H.J. Lunsford, J. Catal. 136 (1992) 566.

[4] R.A. Beyerlein, G.B. McVicker, L.N. Yacullo, J.J. Ziemiak, J. Phys. Chem. 92 (1988) 1967.

[5] D.H. Olson, W.O. Haag, R.M. Lago, J. Catal. 61 (1980) 390.

[6] W.O. Haag, R.M. Lago, P.B. Weisz, Nature 309 (1984) 589.

[7] D. Barthomeuf, Mater. Chem. Phys. 17 (1987) 49.

[8] R. Carson, E.M. Cooke, J. Dwyer, A. Hinchliffe, P.J. O'Malley, Zeolites as Catalysts, Sorbants and Detergent Builders, Extended Abst. (1988) 151.
[9] E. Kassab, K. Seiti, M. Allavena, J. Phys. Chem. 92 (1988) 6705.

[10] A.G. Ashton, S. Batmanian, D.M. Clark, J. Dwyer, F.R. Fitch, A. Hinchcliffe, F.J. Mochado, Stud. Surf. Sci. Catal. 20 (1985) 101.

[11] R.M. Lago, W.O. Haag, R.J. Mikovsky, D.H. Olson, S.D. Hellring, K.D. Schmitt, G.T. Kerr, in: Y. Murakami, A. Iijima, J.W. Ward (Eds.), Proceedings of the 7th International Zeolite Conference, Elsevier, Amsterdam, 1986, p. 677.

[12] Y. Sendoda, Y. Ono, Zeolites 8 (1988) 101.

[13] N.Y. Topsoe, F. Joensen, E.G. Derouane, J. Catal. 110 (1988) 404.

[14] E. Brunner, H. Ernst, D. Freude, M. Hunger, C.B. Krause, D. Prager, W. Reschetilowski, W. Schwieger, K.H. Bergk, Zeolites 9 (1989) 282.

[15] M.H. Vasques, F. Romoa Ribeiro, N.S. Gnep, M. Guisnet, React. Kinet. Catal. Lett. 38 (1989) 301.

[16] D.B. Lukyanov, Zeolites 11 (1991) 325.

[17] V.L. Zholobenko, L.M. Kustov, V.B. Kazansky, E. Loeffler, U. Lohse, C. Peuker, G. Oehlmann, Zeolites 10 (1990) 304.

[18] R. Carvajal, P.J. Chu, J.H. Lunsford, J. Catal. 125 (1990) 123.

[19] E.A. Lombardo, G.A. Sill, K.W. Hall, J. Catal. 119 (1989) 426.

[20] E. Dempsey, J. Catal. 33 (1974) 497.

[21] E. Dempsey, J. Catal. 39 (1975) 155.

[22] C. Miradatos, D. Barthomeuf, J. Chem. Soc., Chem. Commun. (1981) 39.

[23] W.O. Haag, R.M. Dessau, in: Proceedings of the 8th International Congress on Catalysis, Dechema, Frankfurt am Main, 1984, p. 305.

[24] W.O. Haag, R.M. Dessau, R.M. Lago, Stud. Surf. Sci. Catal. 60 (1991) 255.

[25] T.F. Narbeshuber, H. Vinek, J.A. Lercher, J. Catal. 157 (1995) 388.

[26] M. Temkin, Adv. Catal. 28 (1979).

[27] W.O. Haag, Stud. Surf. Sci. Catal. 84 (1994) 1375.

[28] S.M. Babitz, B.A. Williams, J.T. Miller, R.Q. Snurr, W.O. Haag, H.H. Kung, App. Catal. A 179 (1999) 71.

[29] A. Van de Runstraat, P.J. Stobbelaar, J. Van Grondelle, B.G. Anderson, L.J. Van Ijzendoorn, R.A. Van Santen, Stud. Surf. Sci. Catal. 105 (1997) 1253.

[30] J.A. van Bokhoven, J.A.Z. Pieterse, M. Tromp, D.C. Koningsberger, J.T. Miller, J.A. Lercher, B.A. Williams, H.H. Kung, J. Catal. 202 (2001) 129.

[31] S. Kotrel, M.P. Rosynek, J.H. Lunsford, J. Phys. Chem. B 103 (1999) 818.

[32] W.K. Hall, E.A. Lombardo, J. Engelhadt, J. Catal. 115 (1991) 611.

[33] R.A. Beyerlein, G.B. McVicker, L.N. Yabullo, J.J. Ziemiak, ACS Div. Petr. Chem. Preprints 31 (1986) 190.

[34] A.L. Biaglow, D.J. Parillo, G.T. Kokotailo, R.J. Gorte, J. Catal. 148 (1994) 213.

[35] E.G. Derouane, J.B. Janos, C. Fernandez, Z. Gabelica, E. Laurent, P. Maljaen, Appl. Catal. 40 (1988) L1.

[36] E.G. Derouane, J.-M. Andre, A.A. Lucas, J. Catal. 110 (1988) 58.

[37] K.A. van Genechten, W. Mortier, Zeolites 8 (1988) 273.

[38] W. Mortier, Stud. Surf. Sci. Catal. 37 (1988) 253.

[39] J. Datka, M. Boczar, React. Kinet. Catal. Lett. 51 (1993) 161.

[40] F. Eder, M. Stockenhuber, J.A. Lercher, J. Phys. Chem. B 101 (1997) 5414.

[41] J. Wei, Ind. Chem. Eng. Res. 33 (1994) 2467.

[42] J.F. Denayer, G.V. Baron, W. Souverijns, J.A. Martens, P.A. Jacobs, Ind. Eng. Chem. Res. 36 (1997) 3242.

[43] J.A. Lercher, A. Brait, K. Seshan, T.F. Narbeshuber, App. Catal. A 146 (1996) 119

[44] T.F. Narbeshuber, PhD thesis, University of Twente, 1994, p. 51.

[45] G.C. Bond, M.A. Keane, J.A. Lercher, Catal. Rev.-Sci. Eng. 42 (2000) 323.

[46] M. Boronat, P. Viruela, A. Corma, Phys. Chem. Chem. Phys. 2 (2000) 3327.

[47] M.V. Frash, R.A. van Santen, Top. Catal. 9 (1999) 191. 